\title{
Growth inhibitory effect of the Src inhibitor dasatinib in combination with anticancer agents on uterine cervical adenocarcinoma cells
}

\author{
ERI TAKIGUCHI, MASATO NISHIMURA, AYUKA MINEDA, \\ TAKAKO KAWAKITA, AKIKO ABE and MINORU IRAHARA \\ Department of Obstetrics and Gynecology, Institute of Biomedical Sciences, \\ Tokushima University Graduate School, Tokushima 770-8503, Japan
}

Received April 10, 2017; Accepted July 11, 2017

DOI: $10.3892 /$ etm.2017.5061

\begin{abstract}
Uterine cervical adenocarcinoma has a poor clinical prognosis when compared with squamous cell carcinoma. Therefore, the development of new treatment strategies for uterine cervical adenocarcinoma is necessary. $\mathrm{Src}$ is a proto-oncogene that is important in cancer progression. Dasatinib is a Src inhibitor that has been reported to be effective when used in combination with anticancer drugs. The present study aimed to confirm Src expression in human cervical adenocarcinoma cell lines and to determine the mechanism underlying the inhibitory effect of dasatinib on Src signaling in vitro. Western blot analysis was performed to investigate Src expression in cervical adenocarcinoma cell lines (HeLa and TCO-2 cells). The cells were cultured for $48 \mathrm{~h}$ with the addition of different concentrations of anticancer drugs (paclitaxel or oxaliplatin). Viable cell count was measured using a colorimetric (WST-1) assay. The concentrations of anticancer agents were fixed according to the results obtained, and the same experiments were performed using the drugs in combination with dasatinib at various concentrations to determine the concentrations that significantly affected the number of viable cells. The presence or absence of apoptosis was investigated using a caspase-3/7 assay. Signal transduction in each cell line was examined using western blotting. Src was activated in the two cell lines, and cell proliferation was significantly suppressed by each anticancer drug in combination with $10 \mu \mathrm{M}$ dasatinib. Caspase-3/7 activity was also increased and Src signaling was suppressed by each anticancer drug in combination with dasatinib. In conclusion, Src is overexpressed in cervical adenocarcinoma cell lines, and dasatinib
\end{abstract}

Correspondence to: Dr Eri Takiguchi, Department of Obstetrics and Gynecology, Institute of Biomedical Sciences, Tokushima University Graduate School, 3-18-15 Kuramoto-cho, Tokushima 770-8503, Japan E-mail: marron10031982@gmail.com

Key words: Src, dasatinib, paclitaxel, oxaliplatin, cervical adenocarcinoma inhibits intracellular Src signaling and causes apoptosis. The results of the present study suggest that Src may be targeted in novel therapeutic strategies for cervical adenocarcinoma.

\section{Introduction}

In 2011, more than 10,000 women in Japan were diagnosed with uterine cervical carcinoma and almost 2,900 succumbed to this disease (1). The major histopathological type of cervical cancer is squamous cell carcinoma, and the second most frequent type is adenocarcinoma, accounting for $15-20 \%$ of cases (2). The incidence of cervical adenocarcinoma is increasing, and its prognosis is poor compared with that of squamous cell carcinoma due to its low response to chemotherapy and radiotherapy $(1,3)$. According to the National Comprehensive Cancer Network guidelines, treatment of cervical cancer is stratified by stage (3). However, the same treatment is used for adenocarcinoma and squamous cell carcinoma of the cervix (4). Therefore, a novel therapy for cervical adenocarcinoma is required.

Src is a non-receptor tyrosine kinase protein that interacts with receptor tyrosine kinases. Src binds its own Src homology 2 (SH2) domain with a short peptide sequence containing phosphorylated tyrosine (Tyr 530) at the C-terminal tail, and SH3 is coupled with the proline-rich linker domain. $\mathrm{SH} 2$ and SH3 inactivate the structure of the metabolic region. When Tyr 530 is dephosphorylated, intramolecular interaction is destabilized, leading to autophosphorylation of Tyr 419 and activation of Src (5). Src is an important factor in cell survival, proliferation, angiogenesis and metastasis $(5,6)$. Src family kinases are frequently overexpressed and activated in a variety of epithelial and non-epithelial cancers and contribute to resistance to chemotherapy (7). Thus, Src is being investigated for molecularly targeted therapy in cervical adenocarcinoma.

Dasatinib is an inhibitor of the Src family of tyrosine kinases and of the Bcr-Abl tyrosine kinase (4,5). It was originally approved as a drug for the treatment of chronic myeloid leukemia and Philadelphia chromosome-positive acute lymphoblastic leukemia $(4,5)$. Clinical trials have been conducted using dasatinib in combination with anticancer 
drugs for the treatment of breast, colon, prostate and other cancers (8-17). Single-agent dasatinib has not exhibited any clinical activity in breast, pancreatic, colorectal and ovarian carcinoma $(8,12,13,15)$. However, combination therapy with dasatinib and anticancer drugs has been demonstrated to be clinically effective in the treatment of breast, prostate, ovarian and pancreatic cancers $(9-11,14,16,17)$.

A number of studies have reported Src expression in cervical cancer (18-22). However, data are lacking on its expression in cervical adenocarcinoma. The present study aimed to confirm Src expression in human cervical adenocarcinoma cell lines and to determine the mechanism of inhibition of Src signaling by dasatinib in vitro.

\section{Materials and methods}

Cell lines and cultures. HeLa (RCB0007) and TCO-2 (RCB0689) cells were cultured in Eagle's minimum essential medium (Wako Pure Chemical Industries, Ltd., Osaka, Japan), supplemented with $10 \%$ fetal bovine serum (Thermo Fisher Scientific, Inc., Waltham, MA, USA) and $1 \%$ penicillin-streptomycin solution in $5 \% \mathrm{CO}_{2}$ at $37^{\circ} \mathrm{C}$. These cell lines were derived from women with uterine cervical adenocarcinoma, and were provided by the RIKEN BioResource Center (Tsukuba, Japan) through the National Bio-Resource Project of the Japanese Ministry of Education, Culture, Sports, Science and Technology (MEXT). In vitro experiments were conducted with subconfluent cells.

Drugs and reagents. Anti-Src (cat. no. 2109), anti-phospho (p)-Akt (cat. no. 9271S), anti-p-p44/42 MAPK (Erk1/2) (cat. no. 9101) and anti- $\beta$-actin (cat. no. 4967) antibodies for western blotting were all purchased from Cell Signaling Technology, Inc. (Danvers, MA, USA). Anti-p-Src Y419 (cat. no. AF2685) was purchased from R\&D Systems, Inc. (Minneapolis, MN, USA). Dasatinib (Focus Biomolecules, Plymouth Meeting, PA, USA) was prepared as a 10-mmol/1 stock solution in dimethyl sulfoxide (DMSO). Paclitaxel was purchased from Bristol-Myers Squibb (New York, NY, USA) and oxaliplatin was purchased from AdooQ Bioscience (Irvine, CA, USA).

Cytotoxicity assays. The cytotoxicity of paclitaxel, oxaliplatin and the combination of each of these drugs with dasatinib in HeLa and TCO-2 cells was examined using the Cell Proliferation reagent WST-1 (Roche Applied Science, Penzberg, Germany) according to the manufacturer's instructions. The cells were seeded in 96-well plates (5,000 cells/well) with serum-containing medium and incubated for $24 \mathrm{~h}$. The medium was then replaced with $100 \mu \mathrm{l}$ fresh serum free medium containing various concentrations of drug: Paclitaxel $(0,0.0005,0.001,0.005,0.01,0.05,1$ and $10 \mu \mathrm{g} / \mathrm{ml})$, oxaliplatin $(0,0.1,0.5,1,5,10,50,100$ and $500 \mu \mathrm{g} / \mathrm{ml})$, and dasatinib $(0,0.0001,0.001,0.01,0.1,1,10$ and $100 \mu \mathrm{M})$. Treatment was stopped at $48 \mathrm{~h}$, and the WST-1 reagent was added to each well. Following a 2 -h incubation period at $37^{\circ} \mathrm{C}$ and $5 \% \mathrm{CO}_{2}$, the absorbance at $450 \mathrm{~nm}$ of the samples against a background control as blank was measured using a microplate reader (Thermo Fisher Varioskan Flash; Thermo Fisher Scientific, Inc.). Each sample was analyzed in triplicate.

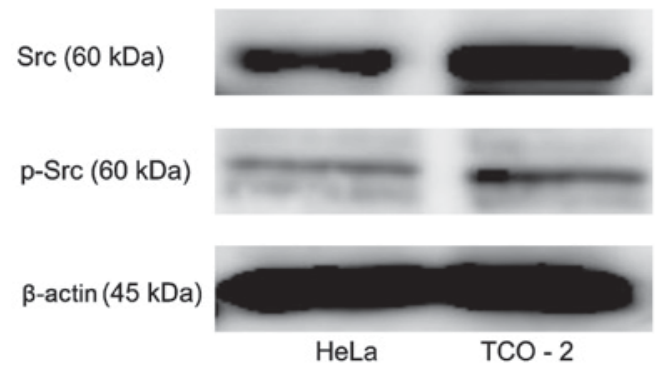

Figure 1. Src and p-Src (Tyr 416) expression in HeLa and TCO-2 cell lines. Protein levels were examined using western blot analysis.

Apoptosis assay. For evaluation of apoptosis, caspase-3/7 activity was measured. The cells were plated at 5,000 cells/well in black 96-well plates and incubated for $24 \mathrm{~h}$. The cells were then treated with either paclitaxel $(0.005 \mu \mathrm{g} / \mathrm{ml})$ or oxaliplatin $(5 \mu \mathrm{g} / \mathrm{ml})$ in the presence or absence of dasatinib $(10 \mu \mathrm{M})$ for $48 \mathrm{~h}$. Following the treatment, $100 \mu \mathrm{l}$ reagent from the Apo-ONE Homogeneous Caspase-3/7 assay kit (Promega Corporation, Fitchburg, WI, USA) was added to each well, which contained $100 \mu \mathrm{l}$ blank, control or treated cells in culture. The plates were gently mixed with a plate shaker at $500 \mathrm{rpm}$ for $30 \mathrm{sec}$. The fluorescence of each well was measured using a microplate reader (Thermo Fisher Varioskan Flash) with a $480 / 520$ excitation/emission filter and a gain setting of 25 .

Western blotting. Cells were harvested to $80 \%$ confluence, and dasatinib and anticancer agents were added as indicated. Cells were lysed in M-PER Mammalian Protein Extraction reagent (Thermo Fisher Scientific, Inc.). Protein concentrations were measured with a Pierce BCA Protein Assay kit (Thermo Fisher Scientific, Inc.). The total protein $(10 \mu \mathrm{g})$ was separated by $7.5 \%$ SDS-PAGE and transferred electrophoretically onto a polyvinylidene difluoride membrane. The blots were blocked for $3 \mathrm{~h}$ at room temperature with $3 \%$ bovine serum albumin (Wako Pure Chemical Industries, Ltd.) and then probed with the aforementioned primary antibodies in TBST $(1: 1,000)$ at $4^{\circ} \mathrm{C}$ overnight. Secondary antibody binding was conducted by incubating the blots with peroxidase-conjugated AffiniPure Goat Anti-Rabbit IgG $(\mathrm{H}+\mathrm{L})$ from Jackson ImmunoResearch Laboratories, Inc. (West Grove, PA, USA) at a dilution of 1:10,000 for $1 \mathrm{~h}$ at room temperature. Proteins were visualized by incubation with ECL Prime Western Blotting Detection reagent (GE Healthcare, Little Chalfont, UK) and detected with an image analyzer (LAS Amersham Imager 600; GE Healthcare). Anti- $\beta$-actin antibody was used as a positive control. Densitometry was performed to interpret differences in the results using ImageJ software version 1.51 (National Institutes of Health; Bethesda, MD, USA).

Statistical analysis. Statistical analyses were performed using SPSS software, version 20 (IBM Corp., Armonk, NY, USA). Inhibition of cell growth by anticancer agents and/or dasatinib was evaluated using Dunnett's test. One-way analysis of variance with Bonferroni's adjustment was used for the caspase-3/7 assay. DMSO was used for comparison as a negative control. All experiments were performed in triplicate. All P-values were two-sided, and $\mathrm{P}<0.05$ was considered to indicate a statistically significant difference in all statistical analyses. 
A

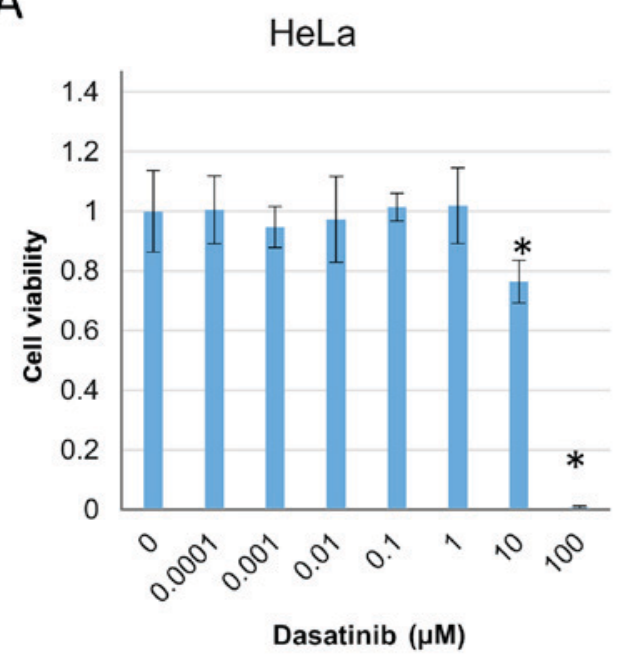

B

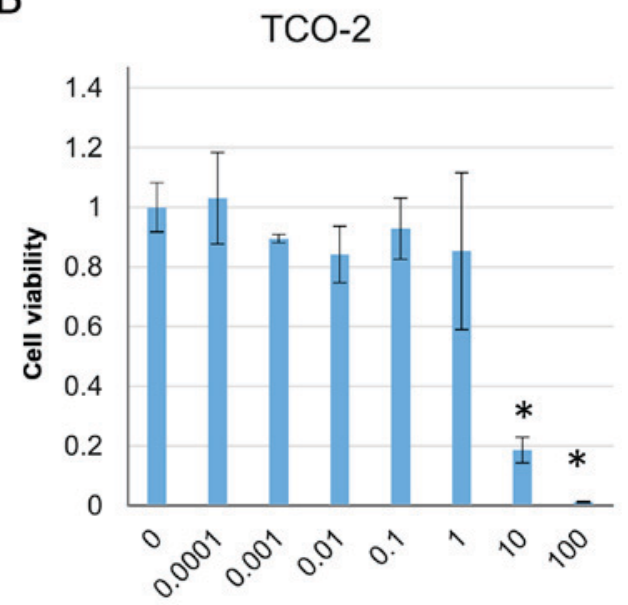

Dasatinib $(\mu \mathrm{M})$

Figure 2. Suppressive effect of dasatinib on cell proliferation in HeLa and TCO-2 cell lines. Cell viability assays were conducted following treatment of (A) HeLa and (B) TCO-2 cell lines with dasatinib for $48 \mathrm{~h}$. ${ }^{*} \mathrm{P}<0.05$ vs. the $0 \mu \mathrm{M}$ dasatinib group. Results are presented as the mean \pm standard error of the mean.

A

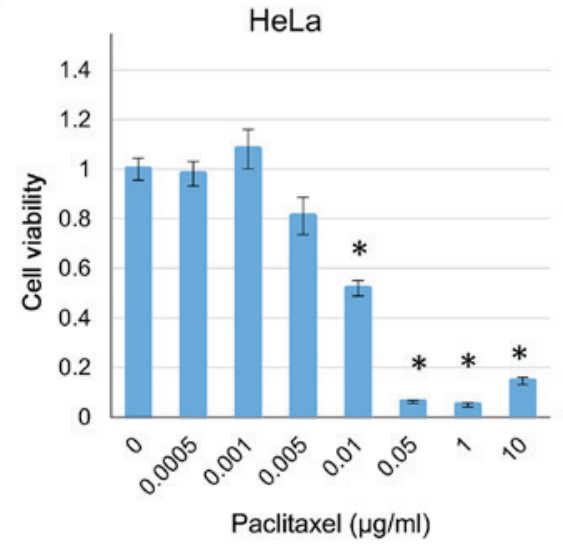

B

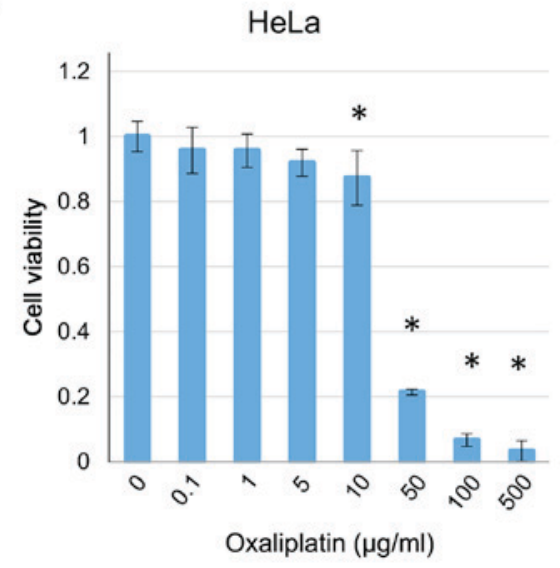

TCO-2

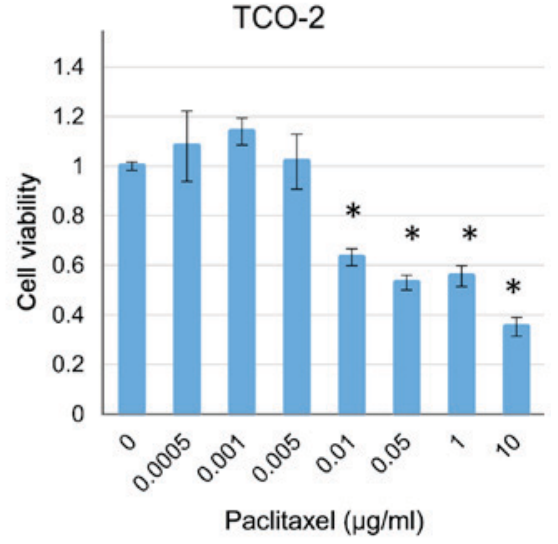

TCO-2

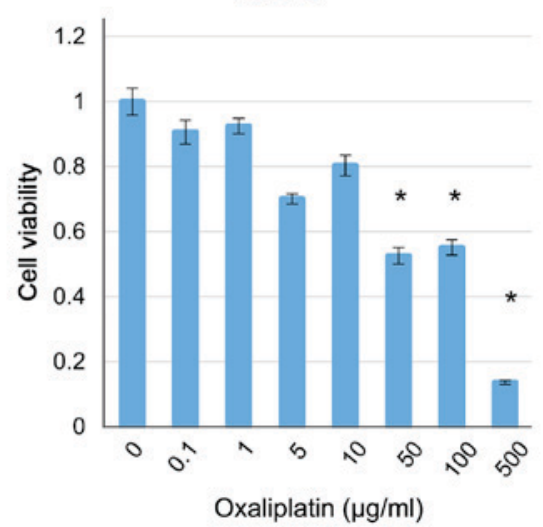

Figure 3. Suppressive effect of anticancer agents on cell proliferation in HeLa and TCO-2 cell lines. Cell viability assays were conducted to determine the viability of HeLa and TCO-2 cell lines following treatment with (A) paclitaxel and (B) oxaliplatin for $48 \mathrm{~h}$. (A) ${ }^{*} \mathrm{P}<0.05 \mathrm{vs}$. the $0 \mu \mathrm{g} / \mathrm{ml}$ paclitaxel group; (B) ${ }^{*} \mathrm{P}<0.05$ vs. the $0 \mu \mathrm{g} / \mathrm{ml}$ oxaliplatin group. Results are presented as the mean \pm standard error of the mean.

\section{Results}

Src and p-Src protein expression in cervical adenocarcinoma cell lines. Src kinase protein expression was evaluated in two cervical adenocarcinoma cell lines using western blot analysis (Fig. 1). The two cell lines clearly exhibited Src and p-Src expression. The TCO-2 cell line exhibited higher expression levels of Src and p-Src than did the HeLa cell line. 
A

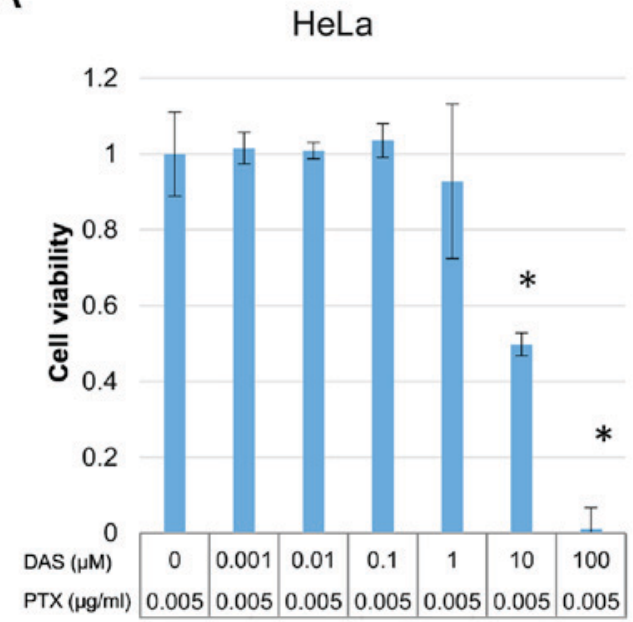

B

HeLa

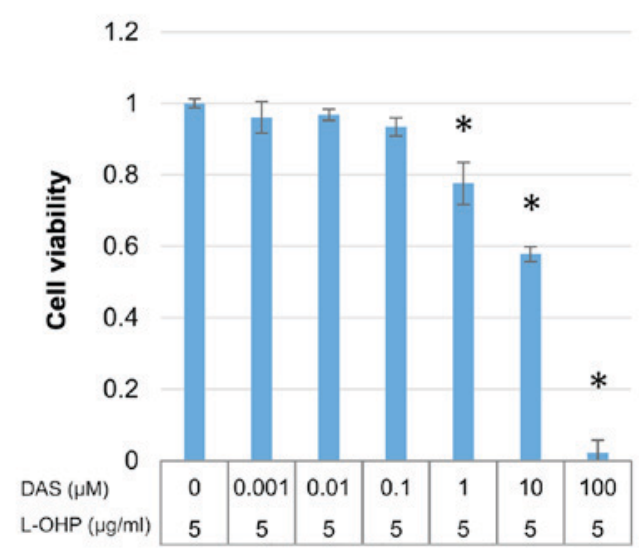

TCO-2

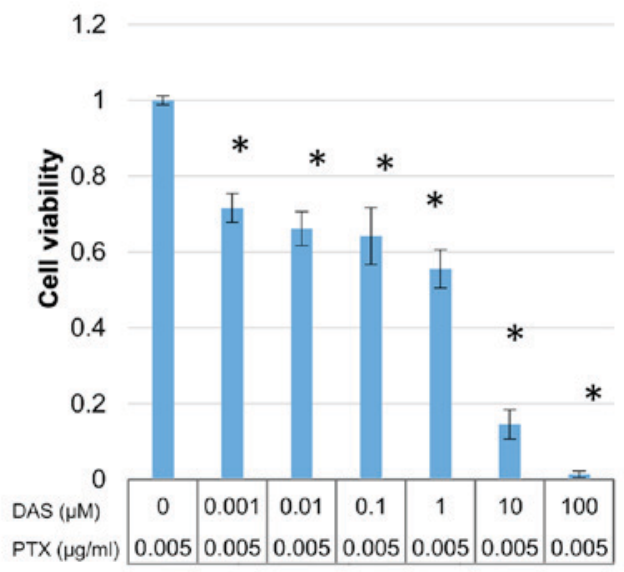

TCO-2

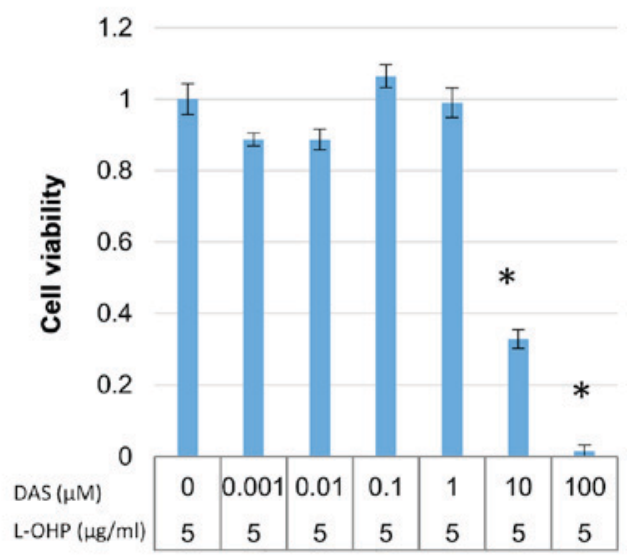

Figure 4. Suppressive effect of dasatinib and anticancer drug combinations on cell proliferation in HeLa and TCO-2 cell lines. Cell viability assays for the combination of (A) PTX and DAS and (B) L-OHP and DAS in HeLa and TCO-2 cell lines following treatment for $48 \mathrm{~h}$. (A) "P $<0.05 \mathrm{vs}$. the $0 \mu \mathrm{M} \mathrm{DAS}+0.005 \mu \mathrm{g} / \mathrm{ml}$ PTX group; (B) "P $<0.05$ vs. the $0 \mu \mathrm{M}$ DAS $+5 \mu \mathrm{g} / \mathrm{ml} \mathrm{L-OHP} \mathrm{group.} \mathrm{Results} \mathrm{are} \mathrm{presented} \mathrm{as} \mathrm{the} \mathrm{mean} \pm$ standard error of the mean. PTX, paclitaxel; DAS, dasatinib; L-OHP, oxaliplatin.

Combinations of dasatinib and anticancer drugs significantly suppress the proliferation of cervical adenocarcinoma cells. The cytotoxic effect of dasatinib was investigated in HeLa and TCO-2 cells using a WST-1 assay. The effect of treatment with various concentrations of dasatinib $(0,0.0001,0.001,0.01,0.1$, $1,10$ and $100 \mu \mathrm{M})$ on cell survival in the two cell lines was evaluated. Cell proliferation was significantly suppressed by treatment with $\geq 10 \mu \mathrm{M}$ dasatinib compared with that in the control group treated with DMSO only (Fig. 2).

The cytotoxicity of paclitaxel and oxaliplatin was also investigated in the HeLa and TCO- 2 cell lines. Treatment with each drug suppressed cell growth in a dose-dependent manner (Fig. 3). Based on these results, the concentrations of paclitaxel and oxaliplatin were fixed (paclitaxel $0.005 \mu \mathrm{g} / \mathrm{ml}$, oxaliplatin $5 \mu \mathrm{g} / \mathrm{ml}$ ) as they were the highest concentrations that did not have a cytotoxic effect, and various concentrations of dasatinib were used with each of the two anticancer drugs. In all cases, when compared with the group receiving the anticancer drug alone (control), a significant difference was observed with the use of $\geq 10 \mu \mathrm{M}$ dasatinib (Fig. 4). Therefore, a decision was made to culture the cells with $10 \mu \mathrm{M}$ dasatinib and collect the protein for analysis.

Combination of dasatinib with anticancer agents causes apoptosis in HeLa and TCO-2 cells. The activity of caspase-3/7 was measured using a caspase-3/7 assay kit in order to investigate the apoptosis associated with combination treatment (Fig. 5). The anticancer drug alone, dasatinib alone, and the anticancer drug plus dasatinib combination groups were compared to determine whether there were differences between the groups. The induction of caspase-3/7 was significantly increased in the combination group when compared with control group (DMSO only), suggesting the induction of cell death by apoptosis.

Combination of dasatinib with anticancer agents inhibits the level of p-Src expression and downstream signal transduction. Src signaling was investigated, with the use of western blot analysis to evaluate $\mathrm{p}$-Src, $\mathrm{p}$-Akt, and p-Erk expression (Fig. 6). When dasatinib was used in combination with an 
A

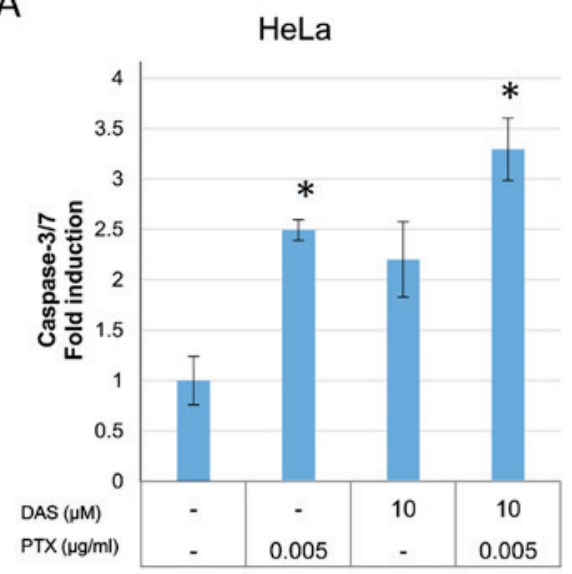

TCO-2

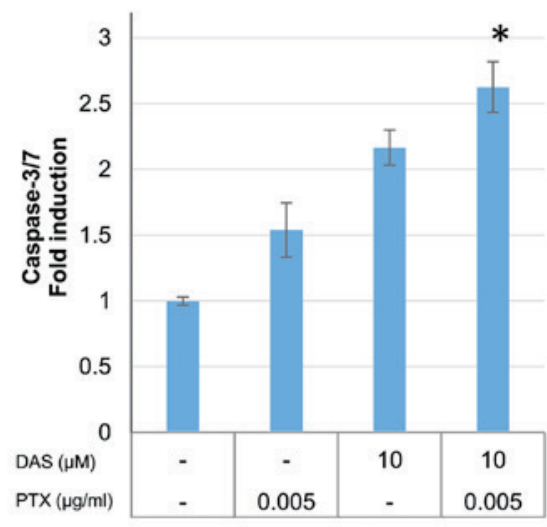

B

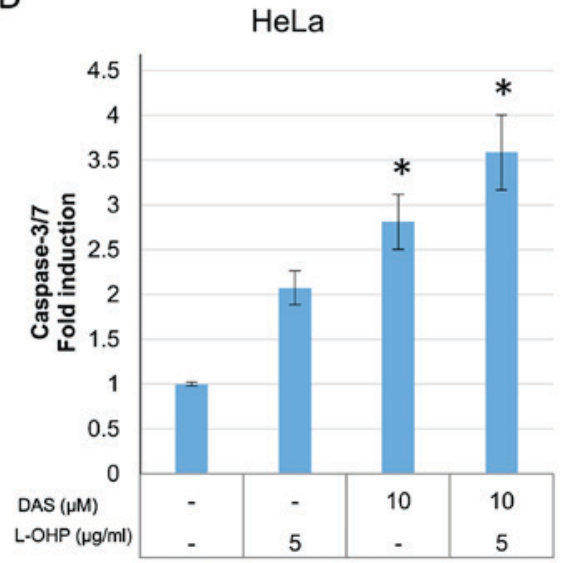

TCO-2

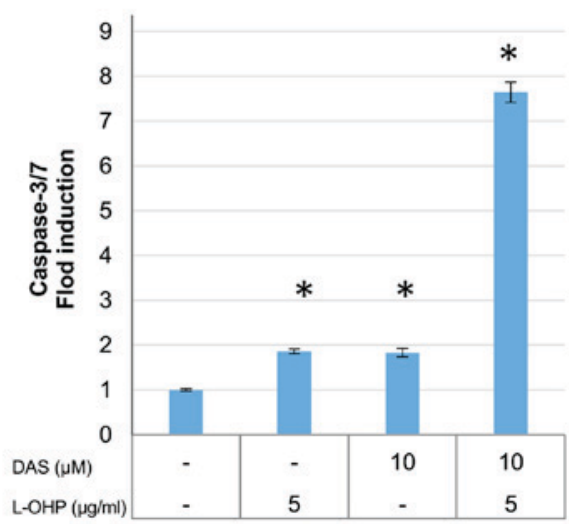

Figure 5. Effect of dasatinib and anticancer agents, alone or in combination, on caspase-3/7 in HeLa and TCO-2 cells. Cells were treated with (A) DAS $(10 \mu \mathrm{M})$ or PTX $(0.005 \mu \mathrm{g} / \mathrm{ml})$ alone, or in combination, or with (B) DAS $(10 \mu \mathrm{M})$ or L-OHP $(5 \mu \mathrm{g} / \mathrm{ml})$ alone, or in combination for $48 \mathrm{~h}$ and compared with an untreated control group. Caspase-3/7 activities were measured. ${ }^{*} \mathrm{P}<0.05$ vs. the untreated control. Results are presented as the mean \pm standard error of the mean. PTX, paclitaxel; DAS, dasatinib; L-OHP, oxaliplatin.

anticancer agent, the Src phosphorylation was suppressed, and phosphorylation in the downstream Akt and MAPK pathways was also inhibited (4).

\section{Discussion}

The purpose of this study was to confirm Src expression in human cervical adenocarcinoma cell lines and to determine the mechanism underlying the inhibition of Src signaling by dasatinib at the cellular and protein levels. The present authors performed an immunohistochemical analysis to reveal Src expression in human adenocarcinoma cells. A total of 49 specimens were obtained from patients who underwent surgery between 2001 and 2011 at the Tokushima University Hospital (Tokushima, Japan). In the normal cervical gland tissue, Src expression was not observed (0/12). In the invasive cervical adenocarcinoma tissue, the expression rate of Src was $44 \%$ (16/36), which was significantly higher than that in the normal cervical gland tissue (data not shown). This demonstrated that Src was expressed in human adenocarcinoma cell lines. In HeLa and TCO-2 cell lines, cell proliferation was significantly suppressed and apoptosis was significantly induced by dasatinib in combination with paclitaxel or oxaliplatin in the present study. Dasatinib in combination with paclitaxel or oxaliplatin suppressed Src phosphorylation and also suppressed downstream signaling via the Akt and MAPK pathways, as determined by western blot analysis. These results support the hypothesis that Src is expressed in cervical adenocarcinoma and that antitumor drugs become more effective when Src signaling is inhibited.

Uterine cervical carcinoma is one of the most serious diseases worldwide, and surgery, chemotherapy and radiotherapy have been used to treat it $(2,4)$. Patients in the advanced stage in various solid tumors show resistance to treatment, and a number of studies have investigated novel antitumor agents, with a particular focus on molecularly targeted drugs. In recent years, Src inhibitors have been studied extensively (8-17).

Clinical trials have revealed no effect of dasatinib alone on breast, pancreatic, colorectal and ovarian tumor progression, overall survival or progression-free survival $(8,12,13,15)$. This may be due to the activation of other signaling molecules, such as the Src family kinases Janus kinase and FGR (14). However, combination therapy with dasatinib and anticancer drugs has been found to be effective for inhibiting tumor growth $(9-11,14,16,17)$. These results are consistent with a number of in vitro experiments (18-22) and the present study. 
A

\begin{tabular}{lcccc} 
A & \multicolumn{4}{c}{ Hela } \\
\cline { 2 - 5 } PTX $(\mu \mathrm{g} / \mathrm{ml})$ & - & 0.005 & - & 0.005 \\
Dasatinib $(\mu \mathrm{M})$ & - & - & 10 & 10
\end{tabular}

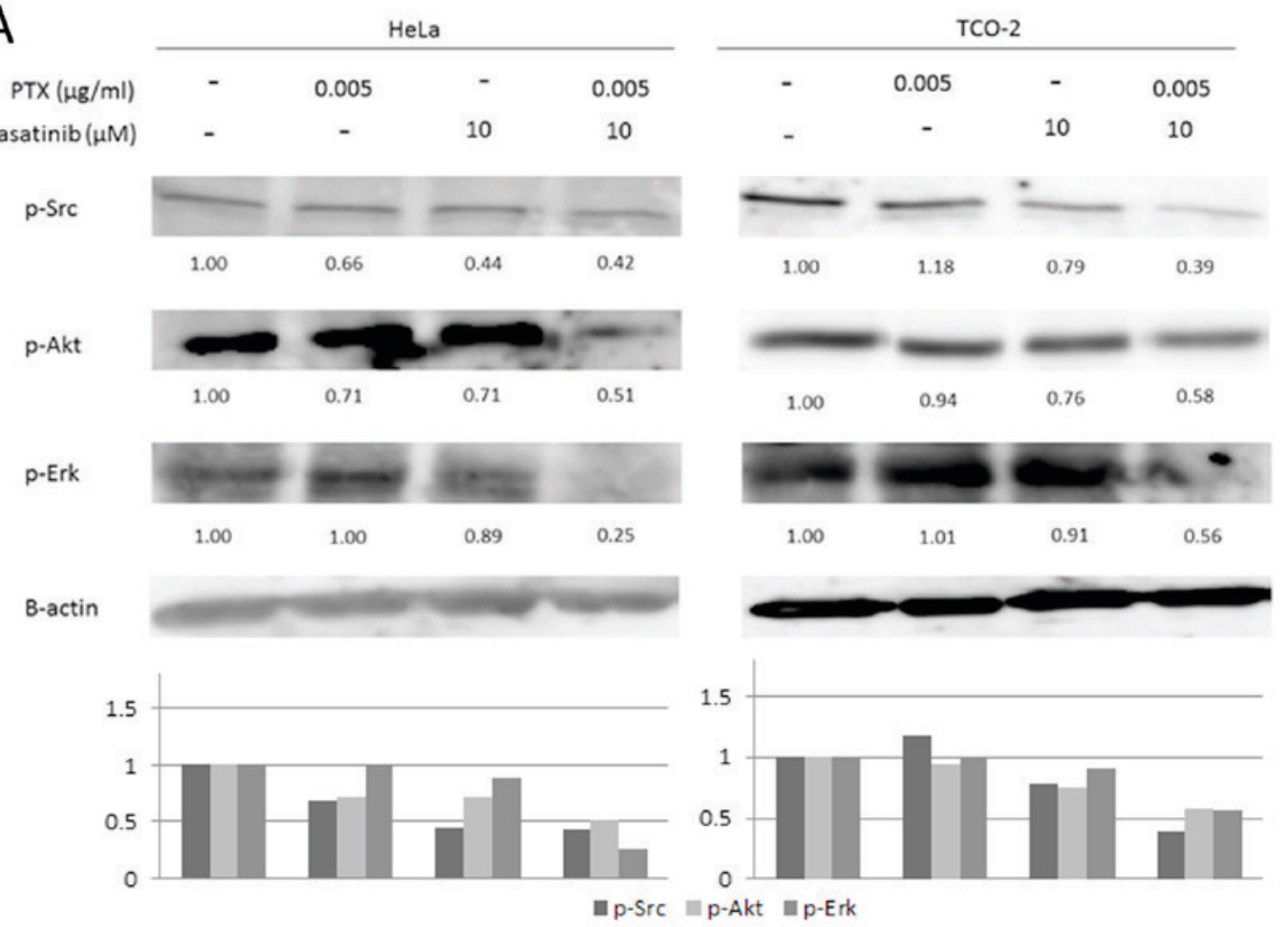

B
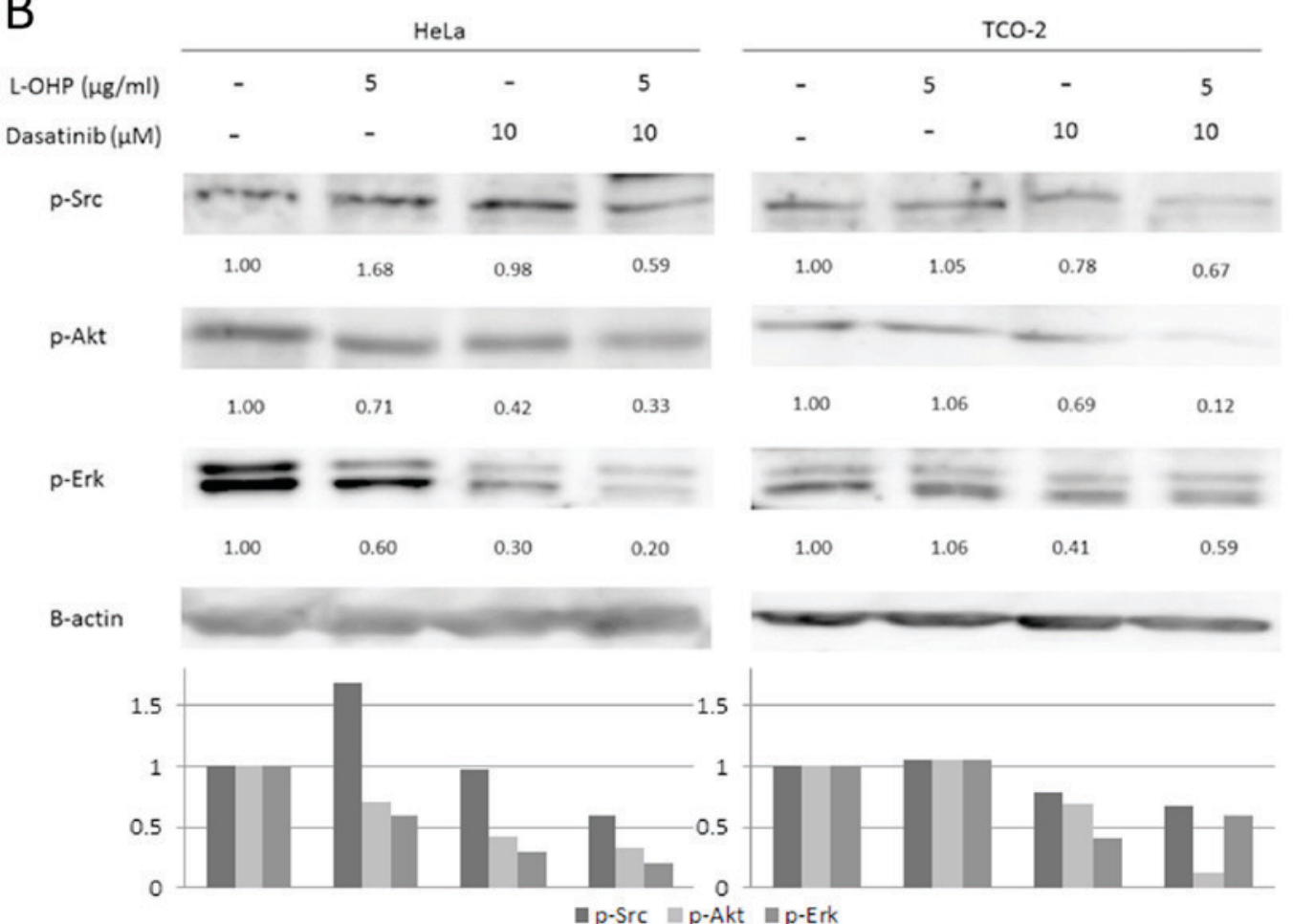

Figure 6. Western blotting results showing p-Src, p-Akt and p-Erk expression in HeLa and TCO-2 cells treated with (A) dasatinib (10 $\mu \mathrm{M})$ or PTX (0.005 $\mu \mathrm{g} / \mathrm{ml})$ alone or in combination, or with (B) dasatinib $(10 \mu \mathrm{M})$ or L-OHP $(5 \mu \mathrm{g} / \mathrm{ml})$ alone or in combination for $48 \mathrm{~h}$. PTX, paclitaxel; DAS, dasatinib; L-OHP, oxaliplatin; p, phospho.

Mucinous ovarian carcinoma is resistant to oxaliplatin; however, this resistance was diminished when dasatinib was used in combination with oxaliplatin (17). Combination treatment with dasatinib and paclitaxel has a synergistic effect against cancer through Src signaling (19). The Src inhibitor PP2 has been shown to inhibit cervical cancer cell proliferation via the downregulation of $\mathrm{p}-\mathrm{Src}$ (23), and $\mathrm{p}$-Src is a predictor of relapse of squamous cell carcinoma (24). However, to the best of our knowledge, the effect of Src inhibitors on adenocarcinoma of the uterine cervix has not been reported, and the present study is the first of its kind to delineate Src expression in cervical adenocarcinoma.

In HeLa and TCO-2 cell lines, cell proliferation was significantly suppressed by $\geq 10 \mu \mathrm{M}$ dasatinib alone. When dasatinib 
was combined with a non-cytotoxic concentration of paclitaxel or oxaliplatin, $\geq 1 \mu \mathrm{M}$ dasatinib significant suppressed cell proliferation in the majority of cases. This indicates that combining dasatinib with an anticancer drug enhances the suppression of cell growth.

In the present study, western blotting results indicated that not all the phosphorylated proteins tested (p-Src, p-Akt and p-Erk) were activated by paclitaxel or oxaliplatin alone compared with controls. However, the anticancer agents alone also did not reliably suppress the activation of phosphorylated proteins, suggesting that they alone do not necessarily increase resistance. Cervical adenocarcinoma cells may respond in a different manner than do mucinous ovarian cancer cells. Although the concentrations of dasatinib used in the experiments in the present study were not sufficient to suppress the expression of the phosphorylated proteins, suppression was observed when dasatinib was used in combination with an anticancer agent compared with the control. The results indicate that Src signaling may be suppressed by combining an anticancer agent with dasatinib. However, the effect of the suppression of Src in vivo is unclear. Further studies are required to identify the mechanism underlying the effects of dasatinib in animal models.

In conclusion, Src is expressed in cervical adenocarcinoma cell lines. Dasatinib inhibits intracellular Src signaling and causes apoptosis. The results of the present study suggest that anti-Src molecularly targeted therapy may be used as a novel treatment strategy for cervical adenocarcinoma.

\section{Acknowledgements}

The authors thank Dr. Takeshi Iwasa for useful discussions and advice. The present study was supported by the Support Center for Advanced Medical Sciences, Institute of Biomedical Sciences, Tokushima University Graduate School.

\section{References}

1. The Editorial Board of the Cancer Statistics in Japan: Cancer Statistics in Japan 2014

2. Fujiwara K, Monk B and Devouassoux-Shisheboran M: Adenocarcinoma of the uterine cervix: Why is it different? Curr Oncol Rep 16: 416, 2014.

3. NCNN Guideline: NCCN Clinical Practice Guidelines in Oncology, cervical cancer, 2016.

4. Gien LT, Beauchemin MC and Thomas G: Adenocarcinoma: A unique cervical cancer. Gynecol Oncol 116: 140-146, 2010.

5. Wheeler DL, Iida M and Dunn EF: The role of Src in solid tumors. Oncologist 14: 667-678, 2009.

6. Summy JM and Gallick GE: Treatment for advanced tumors: SRC reclaims center stage. Clin Cancer Res 12: 1398-1401, 2006.

7. Le XF and Bast RC Jr: Src family kinases and paclitaxel sensitivity. Cancer Biol Ther 12: 260-269, 2011.

8. Schott AF, Barlow WE, Van Poznak CH, Hayes DF, Moinpour CM, Lew DL, Dy PA, Keller ET, Keller JM and Hortobagyi GN: Phase II studies of two different schedules of dasatinib in bone metastasis predominant metastatic breast cancer: SWOG S0622. Breast Cancer Res Treat 159: 87-95, 2016.
9. Fornier MN, Morris PG, Abbruzzi A, D'Andrea G, Gilewski T, Bromberg J, Dang C, Dickler M, Modi S, Seidman AG, et al: A phase I study of dasatinib and weekly paclitaxel for metastatic breast cancer. Ann Oncol 22: 2575-2581, 2011.

10. Araujo JC, Mathew P, Armstrong AJ, Braud EL, Posadas E, Lonberg M, Gallick GE, Trudel GC, Paliwal P, Agrawal S and Logothetis CJ: Dasatinib combined with docetaxel for castration-resistant prostate cancer: Results from a phase 1-2 study. Cancer 118: 63-71, 2012

11. Araujo JC, Trudel GC, Saad F, Armstrong AJ, Yu EY, Bellmunt J, Wilding G, McCaffrey J, Serrano SV, Matveev VB, et al: Docetaxel and dasatinib or placebo in men with metastatic castration-resistant prostate cancer (READY): A randomised, double-blind phase 3 trial. Lancet Oncol 14: 1307-1316, 2013.

12. Chee CE, Krishnamurthi S, Nock CJ, Meropol NJ, Gibbons J, Fu P, Bokar J, Teston L, O'Brien T, Gudena J, et al: Phase II study of dasatinib (BMS-354825) in patients with metastatic adenocarcinoma of the pancreas. Oncologist 18: 1091-1092, 2013.

13. Sharma MR, Wroblewski K, Polite BN, Knost JA, Wallace JA, Modi S, Sleckman BG, Taber D, Vokes EE, Stadler WM and Kindler HL: Dasatinib in previously treated metastatic colorectal cancer: A phase II trial of the University of Chicago Phase II Consortium. Invest New Drugs 30: 1211-1215, 2012.

14. Gold K, Lee J, Harun N, Tang X, Price J, Kawedia JD, Tran HT, Erasmus JJ, Blumenschein GR and William WN: A phase I/II study combining erlotinib and dasatinib for non-small cell lung cancer. Oncologist 19: 1040-1041, 2014.

15. Schilder RJ, Brady WE, Lankes HA, Fiorica JV, Shahin MS, Zhou XC, Mannel R, Pathak HB, Hu W, Alpaugh K, et al: Phase II evaluation of dasatinib in the treatment of recurrent or persistent epithelial ovarian or primary peritoneal carcinoma: A gynecologic oncology group study. Gynecol Oncol 127: 70-74, 2012.

16. Secord AA, Teoh DK, Barry WT, Yu M, Broadwater G, Havrilesky LJ, Lee PS, Berchuck A, Lancaster J and Wenham RM: A phase I trial of dasatinib, a Src-family kinase inhibitor, in combination with paclitaxel and carboplatin in patients with advanced or recurrent ovarian cancer. Clin Cancer Res 18: 5489-5498, 2013

17. Hong DS, Choe DH, Naing A, Wheler JJ, Falchook GS, Piha-Paul S, Moulder SL, George GC, Choe JM, Strauss LC, et al: A phase 1 study of gemcitabine combined with dasatinib in patients with advanced solid tumors. Invest New Drugs 31: 918-926, 2013.

18. Matsuo K, Nishimura M, Bottsford-Miller JN, Huang J, Komurov K, Armaiz-Pena GN, Shahzad MM, Stone RL, Roh JW, Sanguino AM, et al: Targeting Src in mucinous ovarian carcinoma. Clin Cancer Res 17: 5367-5378, 2011.

19. Pengetnze Y, Steed M, Roby KF, Terranova PF and Taylor CC: Src tyrosine kinase promotes survival and resistance to chemotherapeutics in a mouse ovarian cancer cell line. Biochem Biophys Res Commun 309: 377-383, 2003.

20. Xiao J, Xu M, Hou T, Huang Y, Yang C and Li J: Dasatinib enhances antitumor activity of paclitaxel in ovarian cancer through Src signaling. Mol Med Rep 12: 3249-3256, 2015.

21. Teoh D, Ayeni TA, Rubatt JM, Adams DJ, Grace L, Starr MD, Barry WT, Berchuck A, Murphy SK and Secord AA: Dasatinib (BMS-35482) has synergistic activity with paclitaxel and carboplatin in ovarian cancer cells. Gynecol Oncol 121: 187-192, 2011.

22. Liu T, Hu W, Dalton HJ, Choi HJ, Huang J, Kang Y, Pradeep S, Miyake T, Song JH, Wen Y, et al: Targeting Src and tubulin in mucinous ovarian carcinoma. Clin Cancer Res 19: 6532-6543, 2013.

23. Kong L, Deng Z, Zhao Y, Wang Y, Sarkar FH and Zhan Y: Down-regulation of phospho-non-receptor Src tyrosine kinases contributes to growth inhibition of cervical cancer cells. Med Oncol 28: 1495-1506, 2011.

24. Kong L, Deng Z, Shen H and Zhang Y: Src family kinase inhibitor PP2 efficiently inhibits cervical cancer cell proliferation through down-regulating phospho-Src-Y416 and phospho-EGFR-Y1173. Mol Cell Biochem 348: 11-19, 2011. 